\title{
SUSTAINABLE BALANCE OF TRADE DEFICITS
}

\author{
Eric O'N. FISHER* \\ Comell University, Ithaca, NY 14853-7601, USA
}

\begin{abstract}
This paper analyzes a model of overlapping generations in which there are two currencies. There are two agents born in each period, and these agents have completely heterogeneous preferences and endowments. The paper shows that there are monetary equilibria in which one country can sustain a trade deficit whose present value is arbitrarily close to that of its trading partner's entire stream of resources. Hence, there may be no limit to the present value of a country's trade deficit, even if the equilibrium for the world economy satisfies an intertemporal efficiency criterion.
\end{abstract}

\section{Introduction}

The purpose of this paper is to show that monetary policies can give rise to arbitrarily large imbalances of trade in models of overlapping generations. In these models, when one agent is born in each period, a monetary policy has real economic effects through the intergenerational transfers that it facilitates. In international economics, it is natural to consider models in which there are several agents in each generation. Hence, it is possible for monetary policies to give rise to both intergenerational and intragenerational transfers of resources. If we identify sequences of agents with countries, then the net transfers between them are trade surpluses or deficits. We show below that, for any specification of the sequences of endowments and preferences, any trade profile is consistent with some (world) monetary policy. In essence, no matter what the savings preferences and endowments of different countries are, monetary policies alone can have arbitrarily large real international effects.

*I would like to thank Karl Shell and Tapan Mitra for helpful conversations and for stimulating my interest in these subjects. I have had helpful comments from seminar participants at Cornell University, New York University, the University of Quebec at Montreal, the 1989 Buffalo/Cornell/Rochester Theory Conference, and the Fall 1989 Midwest International Economics Meetings. An anonymous referee helped greatly to sharpen the focus of this paper, and the editors of this Journal improved its exposition. I would also like to thank the Center for Analytic Economics at Cornell University for its support. Any errors are due to my own muddy thinking. 
International economists have known that there are general equilibria in which there are imbalances of trade since David Gale's (1971) important contribution. Indeed, Gale noted that dynamic general equilibrium models with heterogeneous agents in which there is balanced trade are the exception rather than the rule. In Gale's model, agents accumulate real physical capital as a store of value; technologies are identical across countries and trade imbalances arise because of differences in savings rates. Although there was no financial asset in his model, Gale conjectured that monetary policies might be a source of imbalances of trade. This paper extends Gale's result by describing exchange economies in which financial assets, not physical capital, serve as stores of value. These economies are completely heterogeneous; preferences, endowments, and monetary policies are entirely general, and we do not confine our attention to steady states.

Some economists object to the role money plays in models of overlapping generations; they argue that these models are more descriptions of social security schemes than they are models of money. ${ }^{1}$ We feel, however, that these criticisms are much less valid in models of international finance. Balance-of-payments accounting serves as a tedious reminder that a current account deficit is simply the sum of the capital account surplus and the loss of official reserves. Under a regime of flexible exchange rates, the change in official reserves is negligible. Hence, the modern approach to modeling external disequilibria focuses upon the forces influencing the adjustment of an economy's stock of net foreign assets.

This is of course exactly the way in which closed-economy models of overlapping generations deal with the dynamic pattern of asset accumulation. The analysis in open economies becomes slightly more subtle because international and intergenerational trades occur in each period. We can see then that models of overlapping generations in international finance are really models of the capital account; by focusing on the accumulation of financial assets, one can infer trade patterns for an economy.

Several authors have explored models of overlapping generations in international economics. The work of Kareken and Wallace (1981) is seminal; they showed that the equilibrium level of the exchange rate is indeterminate. Their model has one good per period and uses stationary preferences, endowments, and money-supply processes. Buiter (1981) studies a one-sector growth model in which countries have different rates of time preference, and Sibert (1985) analyzes country-specific tax policies in a similar model. Neither of these models uses financial assets explicitly. Our work focused upon the money-supply processes as the determinant of trade patterns; the central question we address is what kinds of trade imbalances can be sustained by

\footnotetext{
${ }^{1}$ See Tobin's (1980) discussion in Kareken and Wallace (editors), Models of Monetary Economies, for a spirited critique.
} 
monetary policies in which the exchange rate is well defined. We show below that almost any trade deficit can be sustained by the appropriate monetary policies.

The rest of this paper is structured as follows. The second section presents a sharply focused example to illustrate the main results of this research. Section 3 presents a general model in which there are two moneys; in this model, there are finitely many commodities in each period and agents have heterogeneous endowments and preferences. The fourth section establishes the main result, and section 5 is a brief conclusion.

\section{An example of monetary policy as a source of trade imbalance}

In order to whet the reader's appetite for the general analysis in the next two sections, we present a simple example of a monetary policy that gives rise to an infinitely large trade deficit. An important feature of this example is that the monetary policy we describe makes every agent in the world economy better off than in the nonmonetary equilibrium. Hence, the existence of this world monetary policy and its concomitant trade imbalance is a strong Pareto improvement over the autarkic allocations.

In order to keep the example tractable, we shall assume that there is only one commodity per period; this commodity cannot be stored. We shall assume further that there are two sequences of agents whose preferences and endowments are identical in every respect. There are two old agents at the beginning of time; otherwise, there are two agents born in each period and each agent lives for two periods. Let us call the first sequence of agents Alphas and the second such sequence Betas. The government of the Alphas issues red money and the government of the Betas issues blue money. There are no restrictions placed on the agents participating in the markets for goods, red money or blue money.

We describe now the endowments and preferences of the agents in the world economy. It is convenient to write $G_{t}=\left\{\alpha_{t}, \beta_{t}\right\}$; this is the set of people born in generation $t$. The endowments of agent $h$ are given by $\omega_{h}=(1+\gamma)^{t}$ if $h \in G_{0}$, and $\left.\omega_{h}=\left(3(1+\gamma)^{t}\right),(1+\gamma)^{t}\right)$ if $h \in G_{t}$, with $t \geq 1$. This states that the generation 0 people have one unit of the commodity in their dotage and that the members of any other generation have $3(1+\gamma)^{t}$ units in their youth and $(1+\gamma)^{t}$ in their dotage. The parameter $\gamma>0$ is the per capita rate of growth of the world economy.

The preferences for these agents are summarized by the utility functions $u_{h}=\log c_{h}^{1}$ if $h \in G_{0}$, and $u_{h}=\frac{1}{2} \log c_{h}^{t}+\frac{1}{2} \log c_{h}^{t+1}$ if $h \in G_{t}$, with $t \geq 1$, where we are using the convention that a superscript refers to a dated commodity and that a subscript refers to an agent.

Now let us consider two very simple monetary policies. The monetary policy of the Alpha government consists of giving $2(1+\gamma) /(2+\gamma)$ units of 
red money to Ms. $\alpha_{0}$ and giving $4 \gamma(1+\gamma)^{t} /(2+\gamma)$ units of red money to the old Alpha of generation $t \geq 1$. The monetary policy of the Beta government is less expansionary. It entails giving $2(1+\gamma) /(2+\gamma)$ units of blue money to Ms. $\beta_{0}$ and nothing to anyone else.

As we show below, the exchange rate is constant in a perfect-foresight equilibrium. Now let the exchange rate be one. Without loss of generality, let the price of the consumption good at time one be given by $p^{1}=1$; further let the price of red money at time 1 be one. The international monetary policy $(\mu, \nu)$ is such that the world supply of real balances keeps goods prices stationary. Using a first-order difference equation, it is possible to check that the goods price sequence $p=(1,1, \ldots)$ is indeed an equilibrium.

The Alphas' equilibrium allocations are $1+\mu_{0}$ for Ms. $\alpha_{0}$ and $\left(2(1+\gamma)^{t}+\right.$ $\left.\mu_{t} / 2,2(1+\gamma)^{t}+\mu_{t} / 2\right)$ for Ms. $\alpha_{t}$, with $t \geq 1$. The equilibrium allocations of the Betas are $1+\nu_{0}$ for Ms. $\beta_{0}$ and $\left(2(1+\gamma)^{t}, 2(1+\gamma)^{t}\right)$ for Ms. $\beta_{t}$, with $t \geq 1$. Note that these allocations Pareto dominate those in the nonmonetary equilibrium. This is true even for the alter generations of the Betas; indeed, they are able to use red money as a store of value in order to smooth consumption between youth and old age. Note further that the Alphas consume more than half the world endowment of goods in every period. Because the present-value prices ${ }^{2}$ are constant, this is, in real terms, an infinite trade deficit.

The intuition behind this surprising example is that a growing world economy needs an increasing supply of real balances. Since money serves as a store of value, there are world monetary policies that give rise to equilibria whose allocations are strongly Pareto-superior to those in a nonmonetary equilibrium. If one country gives its citizens money, then it is giving them seigniorage. Since there are absolutely no restrictions on goods markets or financial markets, agents who desire to accumulate real balances that serve as stores of value may do so. The Alphas have more money (of both kinds) than they need, but the Betas do not have enough. Hence, the Betas trade real goods for financial assets. We have constructed the world monetary policy so that the latter-day Alphas always dis-save and their latter-day Beta brethren always acquire red money as a store of value.

The reader may be interested in how the analysis in this paper extends to models of overlapping generations like those in Blanchard and Fischer's influential text (1989). They analyze production economies in which physical capital serves as a store of value and the number of agents (and hence the labor supply) is increasing geometrically. Blanchard and Fischer assume that agents have separable preferences, and their analysis focuses upon stationary models, although they do analyze nonstationary equilibria. They note that monetary equilibria can occur only when the rate of return of money is not

\footnotetext{
${ }^{2}$ It is helpful to think of these as the 'time 1 ' prices of commodities since we have used the normalization that price of consumption good in the first period is one.
} 
dominated by that of physical capital. As will become clear in the analysis below, in an international monetary equilibrium it is necessary that the rates of return of all moneys be equal and that this rate of return be no less than that on real economic investment in any country.

It is worth mentioning that the analysis of a production economy with an increasing labor supply is no more general than that below, because an arbitrary sequence of endowments in an exchange economy can always be interpreted as per capita endowments after the production activity has taken place. Finally, our assumption that preferences are completely heterogeneous is more general than that used in Blanchard and Fischer.

With all this said, the reader may feel that there is something special about the example above, but this is not so. In the next two sections, we show that for any sequence of endowments and preferences in the world economy, virtually any trade pattern can be implemented by some world monetary policy. We hope that this hors d'oeuvre has fortified the reader for the larger course that lies ahead.

\section{The model and equilibrium}

The model is a simple extension of that developed by Balasko and Shell $(1981)^{3}$ in their fundamental paper. In that paper, Balasko and Shell analyze an economy in which there is one agent born in each period. Each agent lives for two periods, and there is one agent who is 'old' at the beginning of the model. Goods cannot be stored, and this gives rise to a role of money as a store of value. The agents have heterogeneous preferences and endowments, and there are $l$ goods available at each point in time. Each agent has preferences such that the closure of her indifference surfaces are contained in the positive orthant of $l$-dimensional or $2 l$-dimensional Euclidean space. Further, each agent is endowed with strictly positive amounts of every good in each period of her life, and the agents are subject to monetary taxes and transfers that are imposed by a central authority.

We extend this model by assuming that there are two agents born in each period, with each agent living for two periods. ${ }^{4}$ There are two people who are old at the beginning of the economy, and they live for only one period. During each period of time, there is a finite number of commodities; these commodities are perishable and cannot be stored. This implies that there may be a role for financial assets as stores of value. We assume that there are two moneys that serve this function.

\footnotetext{
${ }^{3}$ We cite two different papers by these authors. Unless otherwise noted, we always refer implicitly to Balasko and Shell (1981).

${ }^{4}$ Nothing in this analysis depends upon there being only two agents born in each period; this is simply an analytical convenience. Nor does it matter that there are only two moneys or two countries. Indeed, when it suits us below, we shall mention obvious extensions of this model to the case of finitely many agents per period and finitely many fiat moneys.
} 
It will be convenient to represent commodity bundles, prices, and government policies as sequences. The space of allocations is $X=\left(\mathbb{R}_{++}^{l} \times \mathbb{R}_{++}^{l}\right) \times$ $\left(\mathbb{R}_{++}^{2 l} \times \mathbb{R}_{++}^{2 l}\right) \times\left(\mathbb{R}_{++}^{2 l} \times \mathbb{R}_{++}^{2 l}\right) \times \cdots$, and the world economy's sequence of endowments is an element $\omega \in X$. It will be convenient to denote the set of people born at time $t$ by $G_{t}$; we shall think of the two elements of this set as being an Alpha person and a Beta person, both of generation $t$. Let $G_{0}=\left\{\alpha_{0}, \beta_{0}\right\}$ denote the two old people alive at the beginning of the economy. Then $G=\left(G_{0}, G_{1}, \ldots\right)$ represents the world economy's demographic structure.

In these models, there is no sharp distinction between monetary and fiscal policies. It is convenient to call the governments' policy tools lump-sum tax transfers. In a model in which there is one government, such a policy is a sequence of monetary taxes and transfers that are imposed upon the agents in the different periods of their lives. In a setting in which there is more than one government, the description of lump-sum money transfers is more complicated than the usual case. For anyone old at the beginning of the economy, we have $h \in G_{0}$, and a money transfer is given as $\left(m_{h}^{1}, n_{h}^{1}\right) \in \mathbb{R}^{2}$ with the first element of this two-tuple being interpreted as m-money receipts and the second element as $n$-money receipts. For any other agent $h \in G_{t}$ with $t \geq 1$ we have $\left(m_{h}^{t}, n_{h}^{t}, m_{h}^{t+1}, n_{h}^{t+1}\right) \in \mathbb{R}^{4}$ as her lump-sum tax transfers. Let $m \in M$ be a sequence whose typical element is a money transfer, where $M$ is the set of feasible lump-sum money transfers. $M$ can be identified with $\left(\mathbb{R}^{2} \times \mathbb{R}^{2}\right) \times\left(\mathbb{R}^{4} \times \mathbb{R}^{4}\right) \times\left(\mathbb{R}^{4} \times \mathbb{R}^{4}\right) \times \cdots$, where we have taken care again to restate that there are two agents born in each period. Notice that we have already adopted an internationalist perspective because we are considering both $m$-money and $n$-money monetary policies in this description.

The agents in the world economy are free to hold or create as much inside money, of either denomination, as they please. Let $x_{h}^{t, m}$ and $x_{h}^{t, n}$ be the gross additions, at time $t$, to Ms. $h$ 's holdings of $m$-money and $n$-money, respectively. We impose that

$$
\begin{array}{ll}
x_{h}^{t, m} \geq 0 \text { and } x_{h}^{t, n} \geq 0 & \text { for } h \in G_{0}, \\
x_{h}^{t, m}+x_{h}^{t+1, m} \geq 0 \text { and } x_{h}^{t, n}+x_{h}^{t+1, n} \geq 0 & \text { for } h \in G_{l}, \\
& \text { with } t \geq 1,
\end{array}
$$

which has the interpretation that no one can die as a net debtor in either currency and where we have imposed the implicit constraint that no one holds money when she is not alive. ${ }^{5}$ We restrict our attention as usual to

\footnotetext{
${ }^{5} \mathrm{Again}$, we are using the convention that a subscript is the index of an agent and a superscript is the index of a dated commodity or a dated money. Notice that agents can borrow or lend arbitrarily large amounts of either money in the first period of their lives as long as they do not die in debt.
} 
perfectly-foreseen present-value commodity prices; let us call the set of such prices $\mathscr{D} .6$

The consumption choices of the agents satisfy:

$$
\text { maximize } u_{h}\left(x_{h}^{1}\right)
$$

subject to

$$
\begin{aligned}
& p^{1} \cdot x_{h}^{1}+p^{1, m} x_{h}^{1, m}+p^{1, n} x_{h}^{1, n} \\
& \leq p^{1} \cdot \omega_{h}^{1}+p^{1, m} m_{h}^{1}+p^{1, n} n_{h}^{1} \\
& =w_{h}, \\
& x_{h}^{1} \geq 0, \quad x_{h}^{1, m} \geq 0, \quad x_{h}^{1, n} \geq 0 \text { for } h \in G_{0},
\end{aligned}
$$

and

$$
\text { maximize } u_{h}\left(x_{h}^{t}, x_{h}^{t+1}\right) \text {, }
$$

subject to

$$
\begin{aligned}
& p^{t} \cdot x_{h}^{t}+p^{t+1} \cdot x_{h}^{t+1}+p^{t, m} x_{h}^{t, m}+p^{t, n} x_{h}^{t, n} \\
& \quad+p^{t+1, m} x_{h}^{t+1, m}+p^{t+1, n} x_{h}^{t+1, n} \\
& \leq p^{t} \cdot \omega_{h}^{t}+p_{h}^{t+1} \cdot \omega_{h}^{t+1}+p^{t, m} m_{h}^{t}+p^{t, n} n_{h}^{t} \\
& \quad+p^{t+1, m} m_{h}^{t+1, m}+p^{t+1, n} m_{h}^{t+1, n} \\
& =w_{h}, \quad x_{h}^{t, m}+x_{h}^{t+1, m} \geq 0, \quad x_{h}^{t, n}+x_{h}^{t+1, n} \geq 0 \\
& \left(x_{h}^{t}, x_{h}^{t+1}\right) \geq 0, \quad \text { for } h \in G_{t}, \text { with } t \geq 1 .
\end{aligned}
$$

Note that we have implicitly defined $w_{h}$ in these expressions; this is the present value of agent $h$ 's wealth, including the taxes and transfers that accrue to her during the course of her life.

Let us define the aggregate supply of $m$-money and $n$-money in period $t$ as

$$
m^{\prime}=\sum_{s=1}^{t} \sum_{h \in G_{s} \cup G_{s-1}} m_{h}^{s} \text { and } n^{t}=\sum_{s=1}^{t} \sum_{h \in G_{s} \cup G_{s-1}} n_{h}^{s} \text {, }
$$

${ }^{6}$ We adopt the normalization that the price of the consumption good 1 in period 1 is unity. Further, it is important to emphasize that there are many other equilibria in this model. They correspond to intrinsically uncertain realizations of the exchange rate process. An analysis of these equilibria is entirely beyond the scope of this paper. 
where $m^{t} \in \mathbb{R}$ and likewise $n^{t} \in \mathbb{R}$. This allows us to define a monetary competitive equilibrium as a sequence of commodity prices $p \in \mathscr{P}$ and a sequence of money prices $\left(p^{1, m}, p^{1, n}, p^{2, m}, p^{2, n}, \ldots\right)$ satisfying for all $t \geq 1$ :

$$
\begin{aligned}
& \sum_{h \in G_{t} \cup G_{t-1}} x_{h}^{t}=\sum_{h \in G_{t} \cup G_{t-1}} \omega_{h}^{t}, \\
& \sum_{h \in G_{t-1}}\left(x_{h}^{t-1, m}+x_{h}^{t, m}\right)+\sum_{h \in G_{t}} x_{h}^{t, m} \leq m^{t}, \\
& \sum_{h \in G_{t-1}}\left(x_{h}^{t-1, n}+x_{h}^{t, n}\right)+\sum_{h \in G_{l}} x_{h}^{t, n} \leq n^{t},
\end{aligned}
$$

where $x_{h}^{0, m}=x_{h}^{0, n} \equiv 0$ for $h \in G_{0}$.

This definition allows us to state our first proposition:

Proposition 1. Let $p \in \mathscr{P}$ be a goods price sequence in a monetary equilibrium associated with $\omega \in X$ and the intemational monetary policy $M$. Then $p^{t, m}$ and $p^{t, n}$ are both nonnegative constants.

Proof. (This is an extension of Balasko and Shell's Proposition 3.1.) Assume that the price of some money is not a constant. Without loss of generality let this be $m$-money. Then, for some $t, p^{t, m} \neq p^{t+1, m}$. The budget constraint for consumer $h \in G_{t}(t \geq 1)$ can be written as

$$
\begin{aligned}
& p^{t} x_{h}^{t}+p^{t+1} x_{h}^{t+1} \\
& \leq p^{t} \omega_{h}^{t}+p_{h}^{t-1} \omega_{h}^{t+1}+p^{t, m}\left(m_{h}^{t}-x_{h}^{t, m}\right)+p^{t, n}\left(n_{h}^{t}-x_{h}^{t, n}\right) \\
& \quad+p^{t+1, m}\left(m_{h}^{t+1, m}-x_{h}^{t+1, m}\right)+p^{t+1, n}\left(m_{h}^{t+1, n}-x_{h}^{t+1, n}\right), \\
& x_{h}^{t, m}+x_{h}^{t+1, m} \geq 0, \quad x_{h}^{t, n}+x_{h}^{t+1, n} \geq 0 .
\end{aligned}
$$

Since $u_{h}(\cdot)$ is strictly increasing, by setting $x_{h}^{t+1, m}=-x_{h}^{t, m}$, consumer $h$ can choose an arbitrarily large consumption profile $\left(x_{h}^{t}, x_{h}^{t+1}\right) \in \mathbb{P}_{++}^{2 l}$. But this violates the material balances condition

$$
\sum_{h \in G_{l} \cup G_{t-1}} x_{h}^{t}=\sum_{h \in G_{t} \cup G_{t-1}} \omega_{h}^{t} .
$$

Let us now define an international monetary competitive equilibrium as a monetary competitive equilibrium in which $p^{m}>0$ and $p^{n}>0$. This enables us to give a natural definition of the exchange rate. 
Definition. The exchange rate, measured in units of m-money necessary to purchase one unit of $n$-money, is defined by $e^{t}=p^{t, n} / p^{i, m}$.

If $e^{t+1}>e^{t}$, then $m$-money has depreciated in value. We may now state:

Proposition 2. In an international monetary competitive equilibrium, the exchange rate is constant.

Proof. This follows from Proposition 1 and the definition of the exchange rate.

This result is entirely analogous to that of Kareken and Wallace (1981); they call it the dominance result. Kareken and Wallace adopt the normalization that the price of the single consumption good is unity in each period; hence, their result can be interpreted that the real exchange rate is constant. Since we have used the normalization that $p^{1,1}$ is unity, our result states that the present value of the real exchange rate is constant.

In light of Proposition 2, we can use a more convenient notation. Define

$$
\mathscr{Q}=\left\{\left(p, p^{m}, p^{n}\right) \mid p \in \mathscr{P}, p^{m}>0 \text {, and } p^{n}>0\right\} .
$$

We may now state:

Proposition 3. Let $q \in Q$ define an international monetary competitive equilibrium for endowments $\omega \in X$ and lump-sum money transfers $m \in M$. Then the equilibrium goods allocations and money holdings satisfy

$$
\begin{aligned}
p^{1} \cdot\left[\sum_{h \in G_{0}} x_{h}^{1}\right]= & -p^{m}\left[\sum_{h \in G_{0}}\left(x_{h}^{1, m}+e x_{h}^{1, n}-m_{h}^{1}-e n_{h}^{1}\right)\right] \\
& +p^{1} \cdot\left[\sum_{h \in G_{0}} \omega_{h}^{1}\right] \text { if } h \in G_{0},
\end{aligned}
$$

and

$$
\begin{aligned}
& p^{t} \cdot\left[\sum_{h \in G_{l}} x_{h}^{t}\right]+p^{m}\left[\sum_{h \in G_{t}}\left(x_{h}^{t, m}+e x_{h}^{t, n}-m_{h}^{t}-e n_{h}^{t}\right)\right]=p^{t} \cdot\left[\sum_{h \in G_{\jmath}} \omega_{h}^{t}\right], \\
& p^{t+1} \cdot\left[\sum_{h \in G_{l}} x_{h}^{t+1}\right]=-p^{m}\left[\sum_{h \in G_{l}}\left(x_{h}^{t+1, m}+e x_{h}^{t+1, m}-m_{h}^{t+1}-e n_{h}^{t+1}\right)\right] \\
&+p^{t+1} \cdot\left[\sum_{h \in G_{t}} \omega_{h}^{t+1}\right] \text { if } h \in G_{t}, \text { with } t \geq 1 .
\end{aligned}
$$


Proof. These conditions follow from the definition of the exchange rate and Balasko and Shell's Proposition 3.4.

Proposition 4. Let $q \in \mathscr{Q}$ define an international monetary equilibrium for endowments $\omega \in X$ and money transfers $m \in M$. Then

and

$$
\left(x_{h}^{1, n}, x_{h}^{1, n}\right)=(0,0) \quad \text { if } \quad h \in G_{0}
$$

$$
\begin{aligned}
\sum_{h \in G_{t}}\left(x_{h}^{t, m}+e x_{h}^{t, n}\right) & =-\sum_{h \in G_{t}}\left(x_{h}^{t+1, m}+e x_{h}^{t+1, n}\right) \\
& =m^{t}+e n^{t} \quad \text { if } \quad t \geq 1 .
\end{aligned}
$$

Proof. Since we are in an international monetary competitive equilibrium, the price of $m$-money is a constant $p^{m}>0$ and the exchange rate is a constant $e>0$. Then Proposition 3 and the monotony of preferences imply that $\left(x_{h}^{1, m}, x_{h}^{1, n}\right)=(0,0)$ if $h \in G_{0}$; these two facts also imply the first equality in the second line of the proposition above. The money market equilibrium then implies the third equality.

Proposition 4 states that the entire world money supply at time $t$ is held as a store of value by the young of generation $t$ and that it is dis-saved in the second period of their lives. We can call the expression $m^{t}+e n^{t}$ the $m$ money equivalent of the international money supply. Notice that this depends upon the value of the exchange rate $e$.

Recall that the sequence of agents in the world economy is $G=\left(G_{t}\right)$, where $G_{t}=\left\{\alpha_{l}, \beta_{t}\right\}$ for $t \geq 0$. We have a natural definition of nationality:

Definition. Let $\alpha_{t-1}$ be the first element of $G_{t-1}$ and let $\alpha_{t}$ be the first element of $G_{t}$ for $t \geq 1$. Then agent $\alpha_{t-1}$ and agent $\alpha_{t}$ are of the same nationality.

The sequence $\alpha=\left(\alpha_{0}, \alpha_{1}, \ldots\right)$ is identified with the population of the Alpha country, and the sequence $\beta$ is analogous. It is convenient to define the sequence of endowments of the Alpha country by $\omega_{\alpha}=\left(\omega_{\alpha_{0}}^{1}+\omega_{\alpha_{1}}^{1}\right.$, $\left.\omega_{\alpha_{1}}^{2}+\omega_{\alpha_{2}}^{2}, \ldots\right)$ and to define $\omega_{\beta}$ analogously. These sequences represent the entire flow of resources of the Alpha country and the Beta country, respectively.

Definition. Let $\alpha_{t-1}$ be the first element of $G_{t-1}$ and $\alpha_{t}$ be the first element of $G_{t}$. The time 1 value of the trade surplus of the Alpha country at time $t$ is given by

$$
T A^{t}=p \cdot\left[\omega_{\alpha_{t}}^{t}+\omega_{\alpha_{t-1}}^{t}-x_{\alpha_{t}}^{t}-x_{\alpha_{t-1}}^{t}\right] .
$$


This is well defined because only finitely many of the elements of the right side of (3) are not zero. We define the time 1 value of the trade surplus of the Beta country at time $t$ exactly analogously as $T B^{t}$.

Proposition 5. Let $q \in \mathscr{Q}$ define an international monetary equilibrium for endowments $\omega \in X$ and lump-sum money transfers $m \in M$. Let $\alpha_{t-1}$ be the first element of $G_{t-1}$ and let $\alpha_{t}$ be the first element of $G_{t}$ for $t \geq 1$. Then

$$
\begin{aligned}
T A^{t}= & p^{m}\left[\left(x_{\alpha_{t-1}}^{t, m}+e x_{\alpha_{t-1}}^{t, n}-m_{\alpha_{t-1}}^{t}-e n_{\alpha_{t-1}}^{t}\right)\right. \\
& \left.+\left(x_{\alpha_{t}}^{t, m}+e x_{\alpha_{t}}^{t, n}-m_{\alpha_{t}}^{t}-e n_{\alpha_{t}}^{t}\right)\right] .
\end{aligned}
$$

Proof. The trade surplus is given by $p^{t} \cdot\left[\omega_{\alpha_{t}}^{t}+\omega_{\alpha_{t-1}}^{t}-x_{\alpha_{t}}^{t}-x_{\alpha_{t-1}}^{t}\right]$, which is equal to $p^{t} \cdot\left[\omega_{\alpha_{t-1}}^{t}-x_{\alpha_{t-1}}^{t}\right]+p^{t} \cdot\left[\omega_{\alpha_{t}}^{t}-x_{\alpha_{t}}^{t}\right]$. This is simply the value of the excess supply goods in the Alpha country at time $t$. Proposition 3 implies that this is equal to

$$
p^{m}\left(x_{\alpha_{t-1}}^{t, m}+e x_{\alpha_{t-1}}^{t, n}-m_{\alpha_{t-1}}^{t}-e n_{\alpha_{t-1}}^{t}\right)+p^{m}\left(x_{\alpha_{t}}^{t, n}+e x_{\alpha_{t}}^{t, n}-m_{\alpha_{t}}^{t}-e n_{\alpha_{t}}^{t}\right),
$$

where this is of course the value of the excess demand for money in the Alpha country at time $t$.

Eq. (4) has been called the monetary approach to the balance of payments. ${ }^{7}$ It states that the trade surplus is given by the excess demand of at time $t$ for the sum of $m$-money and $n$-money. This proposition is an important aspect of understanding when a trade deficit is sustainable. Notice that the present value of the trade surplus of the Alpha country depends upon the price of $m$-money. Consider lump-sum money transfers $m \in M$ that tend to create an excess supply of money for the Alpha population. Then these will be money transfer schemes that correspond to trade deficits.

Let $T A=\left(T A^{1}, T A^{2}, \ldots\right)$, and let us call the sequence of trade surpluses of the Alpha country its trade profile. Again the present value of this profile depends upon the price of $m$-money. We define the trade profile of the Beta country exactly analogously. Note that $T A=-T B$ in a two-country model.

Let us now formalize the notion of an international monetary policy. We begin by writing $\mu_{0}=\left(m_{\alpha_{0}}^{1}, m_{\beta_{0}}^{1}\right)$ and $\mu_{t}=\left(m_{\alpha_{t}}^{t}+m_{\alpha_{t}}^{t+1}, m_{\beta_{t}}^{t}+m_{\beta_{t}}^{t+1}\right)$ for $t \geq 1$; we defined $\nu_{0}$ and $\nu_{t}$ analogously. These expressions remind us again that we are dealing with two agents born in each period. Since the prices of both moneys are constant in an international monetary competitive equilibrium, we can actually identify a monetary policy with the present value of the sum of taxes and transfers that fall upon agent $h$. This allows us to define an

\footnotetext{
${ }^{7}$ The classic references are Johnson (1961) and the International Monetary Fund's The Monetary Approach to the Balance of Payments (1977).
} 
international monetary policy as two sequences $\mu=\left(\mu_{0}, \mu_{1}, \ldots\right)$ and $\nu=$ $\left(\nu_{0}, \nu_{1}, \ldots\right)$. We shall call $\mu$ an Alpha country monetary policy; likewise $\nu$ is a Beta country monetary policy.

We will be interested in monetary policies that display a simple property. They are such that $\mu_{0}=\left(m_{\alpha_{0}}^{1}, 0\right), \nu_{0}=\left(0, n_{\beta_{0}}^{1}\right)$, and $\mu_{t}=\left(m_{\alpha_{t}}^{t}+m_{\alpha_{t}}^{t+1}, 0\right)$, $\nu_{t}=\left(0, m_{\beta_{t}}^{t}+m_{\beta_{t}}^{t+1}\right)$ for $t \geq 1$. We shall call international monetary policies of this form country-specific monetary policies. They capture the (not entirely realistic) notion that countries tax and give subsidies to their own citizens only. For the rest of the paper, we shall examine only country-specific monetary policies. This is without much loss of generality because, for fixed $p^{m}$ and $e$, any international monetary policy can be implemented by some equivalent country-specific monetary policy.

Let $p \in \mathscr{P}$ and let agent $h$ 's wealth be given by $w_{h l}$, as in eq. (2). Then we can define the individual demand of agent $h$ at time $t$ as $f_{h}^{t}\left(p, w_{h}\right)$. We may now define a Walrasian equilibrium as a price $q=\left(p, p^{m}, p^{n}\right) \in \mathscr{Q}$ such that

$$
\sum_{h \in G} f_{h}\left(p, w_{h}\right)=\sum_{h \in G} \omega_{h} \text { and } w_{h}=p \cdot \omega_{h}+p^{m}\left(\mu_{h}+e \nu_{h}\right) .^{8}
$$

Now let $\mathscr{Q}(\omega, \mu, \nu)$ denote the set of monetary competitive equilibrium. Note that this set depends upon each country's monetary policy. We can now state an important definition.

Definition. The $\omega$-monetary policy $(\mu, \nu)$ is $\omega$-bona fide if $\mathscr{Q}(\omega, \mu, \nu)$ is not empty. The international monetary policy $(\mu, \nu)$ is bona fide if it is $\omega$-bona fide for some $\omega \in X$.

We shall now explore the circumstances under which an international monetary policy is consistent with world endowments given by any fixed $\omega$. In this analysis, we shall take advantage of the fact that there is more than one money in this model. The discussion below serves as a good example of how international monetary economics often permits a greater latitude of analysis than the closed economy monetary economics does.

Let $p \in \mathscr{P}$ and consider the sequence of incomes for the agents in the economy given by $w=\left(w_{\alpha_{1}{ }_{1}}, w_{\beta_{0}}, w_{\alpha_{1}}, w_{\beta_{1}}, \ldots\right)$. Again, we shall occasionally write $w=\left(w_{\alpha}, w_{\beta}\right)$. Now we define the following useful concept:

Definition. The sequence $(p, w)$ is a price-income equilibrium associated with total world resources $r=\left(r^{1}, r^{2}, \ldots\right)$ if and only if $\sum_{h \in G} f_{h}\left(p, w_{h}\right)=r$. The

\footnotetext{
${ }^{8}$ Note that there is no time superscript in this equation; $f_{h}\left(p, w_{h l}\right)$ is the sequence $\left(0, \ldots, 0, f_{h}^{\prime}\left(p, w_{h h}\right), f_{h}^{l+1}\left(p, w_{h}\right), 0, \ldots\right)$ and $w_{h}$ is analogous.
} 
$\omega$-monetary policy $(\mu, \nu)$ is consistent with the price-income equilibrium $(p, w)$ if and only if there is some exchange rate $e>0$ such that $w_{h}=p \cdot \omega_{h}+$ $p^{m}\left(\mu_{h}+e \nu_{h}\right)$ with $h \in G_{t}$ for all $t \geq 0$.

Now consider a given price-income equilibrium $(p, w)$. The following proposition enables us to characterize the international monetary policies that are consistent with this equilibrium:

Proposition 6. The international monetary policy $(\mu, \nu)$ is consistent with the price-income equilibrium $(p, w)$ if and only if

$$
\begin{aligned}
-p^{t+1} \cdot\left[\sum_{h \in G_{l+1}} f_{h}^{t+1}\left(p, w_{h}\right)\right] & <p^{m} \sum_{s=0}^{t}\left(\mu_{s}+e \nu_{s}\right) \\
& <p^{t+1} \cdot\left[\sum_{h \in G_{f}} f_{t}^{t+1}\left(p, w_{h}\right)\right] .
\end{aligned}
$$

Proof. See the appendix.

Although Proposition 6 is only a simple extension of the characterization of a bona fide monetary policy in Balasko and Shell, it is a crucial step in obtaining the main result of this paper. It says that the $m$-money equivalent of the world money supply must satisfy a lower and an upper bound in each period. This implies immediately that if a country-specific monetary policy causes the world supply of real balances to be too large (or too small) at some finite time $t$, then there will never be an international monetary competitive equilibrium. This follows from the usual arguments using backward induction.

Imagine, for example, that the Beta country conducts such an expansionary a monetary policy that (5) is indeed violated. Then the value of $n$-money would be zero for all time, and only $m$-money might serve as a store of value in the world economy. Further, fix $p^{m}$ and consider a value of the exchange rate $e$ such that, given the world monetary policy $(\mu, \nu)$, eq. (5) is eventually violated. Then this exchange rate represents too great a devaluation or revaluation of $n$-money, and such an exchange rate would cause an immediate breakdown of the international monetary competitive equilibrium. This captures the notion of an exchange rate crisis.

\section{Sustainable trade deficits}

The central question that we address in this section is the extent to which monetary policies are consistent with imbalances of trade in this dynamic 
general equilibrium. We begin by establishing a simple result for a nonmonetary world economy. This is an economy where $(\mu, \nu)=0$ identically. Consider a price-income equilibrium, and let us define the sequence $w_{\alpha}$ by the obvious $w_{\alpha}=\left(w_{\alpha_{0}}, w_{\alpha_{1}}, \ldots\right)$, with $w_{\beta}$ being entirely analogous.

Proposition 7. Let totally world resources be given by $r$, and let $\varepsilon \in(0,1)$. Then there is a sequence of endowments $\omega \in X$ satisfying $\sum_{h \in G} \omega_{h}=r$ and a priceincome equilibrium $(p, w)$ such that $\varepsilon w_{\alpha}=w_{\beta}$.

Proof. Let $\varepsilon>0$. Choose $\omega_{\alpha_{0}} \in \mathbb{R}_{++}^{l}$ and $\omega_{\beta_{0}} \in \mathbb{R}_{++}^{l}$ so that $\omega_{\beta_{0}}=$ $(\varepsilon /(1+\varepsilon)) \times \sum_{h \in G_{0}} \omega_{h r}$, and for $t \geq 1$ choose $\omega_{\alpha_{t}} \in \mathbb{R}_{++}^{2 l}$ and $\omega_{\beta_{t}} \in \mathbb{R}_{++}^{2 l}$ likewise so that $\omega_{\beta_{t}}=(\varepsilon /(1+\varepsilon)) \sum_{h \in G_{t}} \omega_{h}$. We are dealing with a model of overlapping generations in which there are four agents alive in each period in which each agent has strictly positive endowments of all goods. Balasko and Shell (1980, proposition 3.11) show that an equilibrium exists for this economy. Let $p \in \mathscr{P}$ be an equilibrium. Recall that $w_{h}=p^{1} \omega_{h}$ for $h \in G_{0}$ and $w_{h}=p^{t} \omega_{h}^{t}+p^{t+1} \omega_{h}^{t+1}$ for $h \in G_{t}$ with $t \geq 1$. Since $\varepsilon \omega_{\alpha_{t}}=\omega_{\beta_{t}}$ for $t \geq 0$, the result is established.

This proposition shows that we can divide the world's resources in such a manner so that the Alphas command an arbitrarily large share of the economy's income in each period. We have also established that we can choose a sequence of endowments $\omega \in X$ such that the $\omega=\left(\omega_{\alpha}, \omega_{\beta}\right)$ represents any division of $r$ that we might desire. The power of Balasko and Shell's (1980) work is that for each such $\omega \in X$ there is an equilibrium in the nonmonetary economy.

We have now developed sufficiently many ideas to prove our main result:

Theorem. Consider any fixed stream of world resources $r$. Then a country can run a trade deficit whose present value is arbitrarily close to the present value of its trading partner's resources.

Proof. Pick a positive $\varepsilon$ in a neighborhood of zero. We shall construct a bona fide international monetary policy consistent with the price-income equilibrium $(p, w)$ we described in Proposition 7.

Let $(p, w)$ be this price-income equilibrium and let $e$ be any arbitrary positive constant. Now define the Betas' monetary policy $\nu$ by

$$
\nu_{0}=\left[[\varepsilon /(1+\varepsilon)] \sum_{h \in G_{0}} p^{1} \cdot \omega_{h}^{1}-\left[p^{1} \cdot \omega_{\beta_{0}}\right]\right] / e
$$


and

$$
\begin{aligned}
\nu_{t}= & {\left[[\varepsilon /(1+\varepsilon)] \sum_{h \in G_{t}}\left(p^{t} \cdot \omega_{h}^{t}+p^{t+1} \cdot \omega_{h}^{t+1}\right)\right.} \\
& \left.-\left[p^{t} \cdot \omega_{\beta_{t}}^{t}+p^{t+1} \cdot \omega_{\beta_{t}}^{t+1}\right]\right] / e \text { for } t \geq 1,
\end{aligned}
$$

where again $\omega_{\beta}$, is the endowment of Ms. $\beta_{t}$. Define the Alphas' countryspecific monetary policy by $\mu_{t}=-e \nu_{t}$ for $t \geq 0$. It is easy to check that $\sum_{s=0}^{t}\left(\mu_{s}+e \nu_{s}\right)=0$ for $t \geq 0$. Hence, these country-specific monetary policies are such that $p^{m}\left[\sum_{s=0}^{t}\left(\mu_{s}+e \nu_{s}\right)\right]=0$ for all $t$. This implies that this international monetary policy is trivially bona fide for this price-income equilibrium.

Recall that the world's stream of resources is given by $r=\Sigma_{h \in G} \omega_{h}$. Of course, the value of each Beta's consumption is equal to her income. The goods market equilibrium condition in each period implies that the value of the consumption of the Alphas can be made arbitrarily close to $p^{t} \cdot r^{t}$, which is of course the present value of the entire world's resources in that period. This implies that the value of the Alpha country's trade deficit can be made arbitrarily close to $p^{t} \omega_{\beta}^{t}$ in each period.

This theorem is true both for cases in which there is a uniform bound on world resources and in ones in which there is no such uniform bound. In the case where there is no uniform bound on world resources, the theorem implies that the present value of the Alpha country's trade deficit can be made arbitrarily large, even if the time 1 prices of goods satisfy an efficiency criterion. Indeed, the example presented in section 2 is exactly this kind of a world economy. This theorem can be interpreted as saying that in a growing world economy in which future goods are priced efficiently, the present discounted value of a country's trade deficit may not be bounded.

The reader may feel that there is something perverse about the theorem because the surplus country Beta is accommodating this equilibrium by punishing itself with monetary contractions. But this is exactly the role that a devaluation plays in international finance. To see this, fix total world resources $r$ and the international monetary policy $(\mu, \nu)$ and then consider a devaluation of $m$-money. For a fixed $m$-money price $p^{m}$, this implies that $e$ rises or equivalently that $p^{n}$ rises. If $(\mu, \nu)$ is $\omega$-bona fide for both the original and new exchange rates, then the devaluation of $m$-money is an expansion of the share of the increase in the world supply of real balances accruing to each citizen of the Beta country. This is precisely how a devaluation 'improves' the trade balance of the Alpha country. The exact effect that such a devaluation will have on the entire pattern of trade is difficult to determine at this level of generality. It will depend upon the profile of 
endowments, the pattern of preferences, and both country-specific monetary policies.

We took advantage of a very important fact in the proof of the theorem. In models of international finance it is always possible to construct nontrivial monetary policies giving rise to equilibria in which the prices of all moneys are not zero. This is not true in a closed economy in which there is a single agent born in each period. The fact that there are two agents born in each period allows us to design monetary policies that are trivially bona fide for any aggregate price-income equilibrium. These policies will always have real effects in the transfer of resources between the agents of one generation, even if there is absolutely no role otherwise for money as a store of value.

The structure of these arguments can obviously be extended to an $n$-country world where $n>2$. We note in passing that any perfect-foresight international monetary equilibrium will have all bilateral exchange rates fixed, and we state a simple corollary of the theorem.

Corollary. Consider an n-country world in which each country can issue fiat money and any fixed endowment $\omega \in S$ satisfying $\sum_{h \in G} \omega_{h}=r$, where each $G_{t}$ is now a set consisting of $n$ elements. Then any division of $r$ that holds each generation's aggregate resources fixed can be implemented by some international monetary policy.

Proof. This follows from a construction analogous to that in the theorem.

\section{Conclusion}

This paper has shown that there are general conditions under which monetary equilibria give rise to arbitrarily large imbalances of trade. By allowing for the use of two moneys as stores of value, it showed that there are always nontrivial monetary equilibria for any international economy. It confirmed in a general setting earlier work that had established that the exchange rate is constant in a perfect-foresight equilibrium. We emphasized throughout the discussion the distinction between the roles money plays in affecting international and intergenerational transfers of resources. Finally, we would be remiss not to mention that the analysis of bona fide international monetary policies gives rise naturally to the study of the set real exchange rates consistent with the monetary policy $(\mu, \nu)$. This is an avenue of research that we hope to pursue in the near future.

\section{Appendix}

Proposition 6. The monetary policy $(\mu, \nu)$ is consistent with the price-income equilibrium $(p, w)$ if and only if (5) obtains. 
Proof. (This proof is an extension of that given by Balasko and Shell for their Proposition 5.5.) Consider the equations

$$
\begin{aligned}
& \sum_{h \in G_{0}} f_{h}^{1}\left(p, w_{h}\right)+\sum_{h \in G_{1}} f_{h}^{1}\left(p, w_{h}\right)=r^{1}, \\
& \vdots \\
& \sum_{h \in G_{t}} f_{h}^{t+1}\left(p, w_{h}\right)+\sum_{h \in G_{t+1}} f_{h}^{t+1}\left(p, w_{h}\right)=r^{t+1} .
\end{aligned}
$$

Let us create the inner products of the first equation with $p^{1}$, the second equation with $p^{2}$, and so on; this sum is well defined because we are considering only finitely many such equations. We obtain

$$
\sum_{s=0}^{t} \sum_{h \in G_{s}} w_{h}-\sum_{s=1}^{t+1} p^{s} \cdot r^{s}=-p^{t+1} \cdot\left[\sum_{h \in G_{t+1}} f_{h}^{t+1}\left(p, w_{h}\right)\right]
$$

and

$$
\begin{aligned}
\sum_{s=0}^{t} \sum_{h \in G_{s}} w_{h}-\sum_{s=1}^{t} p^{s} \cdot r^{s} & =p^{t+1} \cdot\left[r^{t+1}-\sum_{h \in G_{t+1}} f_{h}^{t+1}\left(p, w_{h}\right)\right] \\
& =p^{t+1} \cdot\left[\sum_{h \in G_{r}} f_{h}^{t+1}\left(p, w_{h}\right)\right] .
\end{aligned}
$$

This allows us to replace the expressions in (5) by

$$
\begin{aligned}
\sum_{s=0}^{t} \sum_{h \in G_{s}} w_{h}-\sum_{s=1}^{t+1} p^{s} \cdot r^{s} & <p^{m}\left[\sum_{s=0}^{t}\left(\mu_{s}+e \nu_{s}\right)\right] \\
& <\sum_{s=0}^{t} \sum_{h \in G_{s}} w_{h}-\sum_{s=1}^{t} p^{s} \cdot r^{s}
\end{aligned}
$$

We shall construct a sequence of endowments $\omega=\left(\omega_{\alpha_{0}}, \omega_{\beta_{0}}, \omega_{\alpha_{1}}, \omega_{\beta,}, \ldots\right)$ such that $q=\left(p, p^{m}, p^{n}\right)$ is an international monetary competitive equilibrium associated with $(\omega, \mu, \nu)$.

Let $t=0$. Then the expression $\left(5^{\prime}\right)$ states that

$$
\sum_{h \in G_{0}} w_{h}-p^{1} \cdot r^{1}<p^{m}\left(\mu_{0}+e \nu_{0}\right)<\sum_{h \in G_{0}} w_{h}
$$


which is equivalent to

$$
0<p^{m}\left(\mu_{0}+e \nu_{0}\right)-\sum_{h \in G_{0}} w_{h}+p^{1} \cdot r^{1}<p^{1} \cdot r^{1}
$$

Since

$$
\sum_{h \in G_{0}} w_{h}=\sum_{h \in G_{0}} p^{1} \cdot \omega_{h}^{1}+p^{m} \sum_{h \in G_{0}}\left(\mu_{h}+e \nu_{h}\right)
$$

this expression is equivalent to

$$
\begin{aligned}
0<p^{\prime m}\left(\mu_{0}+e \nu_{0}\right)-\sum_{h \in G_{0}} p^{1} \cdot \omega_{h}^{1}-p^{m} \sum_{h \in G_{0}}\left(\mu_{h}+e \nu_{h}\right) \\
\quad+p^{1} \cdot r^{1}<p^{1} \cdot r^{1}
\end{aligned}
$$

But

$$
p^{m}\left(\sum_{h \in G_{0}} \mu_{h}+e \nu_{h}\right)=p^{m}\left(\mu_{0}+e \nu_{0}\right)
$$

by the definition of the aggregate supply of $m$-money and $n$-money. This implies that $\left(5^{\prime}\right)$ is equivalent to

$$
0<p^{1} \cdot\left[r^{1}-\sum_{h \in G_{0}} \omega_{h}^{1}\right]<p^{1} \cdot r^{1}
$$

Since $r^{1} \in \mathbb{R}_{++}^{l}$ and $p^{1}>0$, we can certainly choose $\omega_{\alpha_{0}}^{1} \in \mathbb{R}_{++}^{\prime}$ and $\omega_{\beta_{0}}^{1} \in$ $\mathbb{R}_{++}^{\prime}$ such that $0<p^{1} \cdot\left[\omega_{\alpha_{0}}^{1}+\omega_{\beta_{0}}^{3}\right]<p^{1} \cdot r^{1}$. Pick such $\omega_{h}^{1}$ for $h \in G_{0}$ and then choose $\omega_{h}^{1} \in \mathbb{R}_{++}^{l}$ for $h \in G_{1}$ such that

$$
\sum_{h \in G_{0}} \omega_{h}^{1}+\sum_{h \in G_{1}} \omega_{h}^{1}=r^{1}
$$

Now, for each $h \in G_{1}$, we need to determine $\omega_{h}^{2} \in \mathbb{R}_{++}^{\prime}$ such that $p^{1} \cdot \omega_{h}^{1}+$ $p^{2} \cdot \omega_{h}^{2}=w_{h}-p^{m}\left(\mu_{h}+e \nu_{h}\right)$ and $\sum_{h \in G_{1}} \omega_{h}^{2}<r^{2}$. Summing over $h \in G_{1}$, we 
see that this is equivalent to

$$
\begin{aligned}
p^{2} \cdot\left[\sum_{h \in G_{1}} \omega_{h}^{2}\right]= & \sum_{h \in G_{1}} w_{h}-p^{m} \sum_{h \in G_{1}}\left(\mu_{h}+e \nu_{h}\right)-p^{1} \cdot\left[\sum_{h \in G_{1}} \omega_{h}^{1}\right] \\
= & \sum_{h \in G_{1}} w_{h}-p^{m} \sum_{h \in G_{1}}\left(\mu_{h}+e \nu_{h}\right)-p^{1} \cdot\left[r^{1}-\sum_{h \in G_{0}} \omega_{h}^{1}\right] \\
= & \sum_{h \in G_{1}} w_{h}-p^{m} \sum_{h \in G_{1}}\left(\mu_{h}+e \nu_{h}\right)-p^{1} \cdot r^{1} \\
& +\sum_{h \in G_{0}} w_{h}-p^{m} \sum_{h \in G_{0}}\left(\mu_{h}+e \nu_{h}\right) \\
\cdot= & \sum_{h \in G_{0}} w_{h}+\sum_{h \in G_{1}} w_{h}-p^{1} \cdot r^{1}-p^{m} \sum_{s=0}^{1}\left(\mu_{s}+e \nu_{s}\right),
\end{aligned}
$$

where we have again used the definition of the aggregate money supplies. Now there are two such $\omega_{h}^{2} \in \mathbb{R}_{++}^{l}$ for $h \in G_{1}$ if and only if $0<$ $p^{2} \cdot\left[\sum_{h \in G_{1}} \omega_{h}^{2}\right]<p^{2} \cdot r^{2}$. Hence,

$$
0<\sum_{h \in G_{0}} w_{h}+\sum_{h \in G_{1}} w_{h}-p^{1} \cdot r^{1}-p^{m} \sum_{s=0}^{1}\left(\mu_{s}+e \nu_{s}\right)<p^{2} \cdot r^{2},
$$

which is equivalent to

$$
\begin{aligned}
\sum_{s=0}^{1} \sum_{h \in G_{s}} w_{h}-p^{1} \cdot r^{1}-p^{2} \cdot r^{2} & <p^{m} \sum_{s=0}^{1}\left(\mu_{s}+e \nu_{s}\right) \\
& <\sum_{s=0}^{1} \sum_{h \in G_{s}} w_{h}-p^{1} \cdot r^{1}
\end{aligned}
$$

This corresponds to $\left(5^{\prime}\right)$ for $t=1$.

We now proceed by induction. We assume that we have determined all $\omega_{h}^{t}$ for $h \in G_{s}$ for $s=0, \ldots, t-1$. This means that we can assume that both $\omega_{h}^{t}$ for $h \in G_{t}$ are determined if and only if $\left(5^{\prime}\right)$ holds for $t-1$. The logic of the system of equations leading to $\left(5^{\prime}\right)$ implies that

$$
p^{t} \cdot\left[\sum_{h \in G_{t}} \omega_{h}^{t}\right]=-\sum_{s=0}^{t-1} \sum_{h \in G_{s}} w_{h}+\sum_{s=1}^{t-1} p^{s} \cdot r^{s}+p^{m}\left[\sum_{s=0}^{t-1}\left(\mu_{s}+e \nu_{s}\right)\right] .
$$


Therefore we need to find $\omega_{h}^{l+1} \in \mathbb{R}_{++}^{l}$ for $h \in G_{t}$ such that each $\omega_{h}^{t+1}$ satisfies $w_{h}=p^{t} \cdot \omega_{h}^{t}+p_{l}^{t+1} \cdot \omega_{h}^{t+1}+\mu_{h}$ for $h \in G_{l}$, with $\sum_{h \in G_{t}} \omega_{h}^{t+1}<r^{+1}$. Again summing over $h \in G_{t}$, we see that these two equalities are equivalent to

$$
p^{t+1} \cdot\left[\sum_{h \in G_{t}} \omega_{h}^{t+1}\right]=\sum_{s=0}^{t} \sum_{h \in C_{s}} w_{h}+\sum_{s=1}^{t} p^{s} \cdot r^{s}+p^{m}\left[\sum_{s=0}^{t}\left(\mu_{s}+e \nu_{s}\right)\right] .
$$

There are such $\omega_{h}^{t+1}$ if and only if $0<p^{t+1} \cdot\left[\sum_{h \in G_{t}} \omega_{h}^{t+1}\right]<p^{t+1} \cdot r^{t+1}$, which is again easily transformed into

$$
0<\sum_{s=0}^{t} \sum_{h \in C_{s}} w_{h}-\sum_{s=1}^{t} p^{\ell} \cdot r^{\prime}-p^{m} \sum_{s=0}^{t}\left(\mu_{s}+e \nu_{s}\right)<p^{t+1} \cdot r^{l+1}
$$

This is equivalent to $\left(5^{\prime}\right)$ for $t>1$.

\section{References}

Balasko, Yves and K. Shell, 1980, The overlapping generations model. I: The case of pure exchange without money, Journal of Economic Theory 23, 280-306.

Balasko, Yves and K. Shell, 1981, The overlapping generations model. II: The case of pure exchange with money, Journal of Economic Theory 24, 112-142.

Blanchard, Olivier J. and Stanley Fischer, 1989, Lectures on macroeconomics (MIT Press, Cambridge, MA).

Buiter, Willem H., 1981, Time preference and international lending and borrowing in an overlapping-generations model, Journal of Political Economy 89, 769-797.

Gale, David, 1971, General equilibrium with imbalance of trade, Journal of International Economics 1, 141-158.

International Monetary Fund, 1977, The monetary approacl to the balance of payments (Internationa! Monetary Fund, Washington, DC).

Johnson, Harry, 1961, Towards a general theory of the balance of payments, in: International trade and economic growth: Studies in pure theory (Harvard University Press, Cambridge, MA) 153-168.

Tobin, James, 1980, Discussion, in: John H. Kareken and Neil Wallace, eds., Models of monetary economies (Federal Reserve Bank of Minneapolis, Minneapolis, MN) 83-90.

Kareken, John $\mathrm{H}$. and Neil Wallace, 1981, On the indeterminacy of the equilibrium exchange rate, Quarterly Journal of Economics 96, 207-222.

Sisbert, Anne C., 1985, Capital accumulation and foreign investment taxation, Review of Economic Studies 52, 331-345. 